Orbis Tertius, vol. XXVI, nº 34, e208, noviembre 2021 - abril 2022. ISSN 1851-7811

Universidad Nacional de La Plata

Facultad de Humanidades y Ciencias de la Educación

Centro de Estudios de Teoría y Crítica Literaria

\title{
Bibliotecas populares elementales: una política de colecciones para las bibliotecas argentinas durante la década de 1910
}

\author{
Elementary popular libraries: a collection policy for Argentine libraries during \\ the 1910s
}

Javier Planas

jplanas@fahce.unlp.edu.ar

Instituto de Investigaciones en Humanidades y

Ciencias Sociales (Universidad Nacional de La Plata-

CONICET), Argentina

Recepción: 20 Febrero 2021

Aprobación: 19 Julio 2021

Publicación: 01 Noviembre 2021

Cita sugerida: Planas, J. (2021). Bibliotecas populares elementales: una política de colecciones para las bibliotecas argentinas durante la década de 1910. Orbis Tertius, 26(34), e208. https://doi.org/10.24215/18517811e208
Resumen: Durante la década de 1910 la Comisión Protectora de Bibliotecas Populares de Argentina formó una colección de libros para fundar bibliotecas en todo el país. El objetivo era consolidar una política cultural de afirmación del sentimiento nacional. Para reconstruir y analizar el catálogo de ese repertorio, se estudia el libro de actas de la entidad, sus publicaciones y otros documentos de interés. Tres aspectos constituyen las variables de análisis: (a) el papel de la Comisión Protectora como productora intelectual de la colección; (b) el modo en el que fueron seleccionados los núcleos temáticos y la manera en que fueron escogidas las obras; (c) las relaciones entre la constitución de una política bibliotecaria y la formación de una colección de lecturas. Entre las principales constataciones, se indica: la confianza en el poder de convencimiento atribuido a la lectura, las características que asumió la colección en relación con los propósitos de su creación y los vínculos con el mercado editorial.

Palabras clave: Bibliotecas populares elementales, Políticas bibliotecarias, Colecciones de bibliotecas, Nacionalismo.

Abstract: During the 1910s, the Comisión Protectora de
Bibliotecas Populares (Commission for the Protection of
Popular Libraries) in Argentina formed a collection of books
to found libraries throughout the country. The objective was
to consolidate a cultural policy of affirmation of national
sentiment. To reconstruct and analyze the catalog of this
repertoire, the entity's minute book, its publications, and other
documents of interest are studied. Three aspects constitute
the variables for analysis: (a) the Commission's role as the
intellectual producer of the collection; (b) the way in which
themes and works were selected; (c) the connections between the
constitution of a library policy and the formation of a collection
of readings. Among the conclusions, the following are observed:
the trust placed on the persuasion powers of reading, the features
developed by the collection in relation to the purposes of its
creation, and the links with the publishing market.

Keywords: Elementary popular libraries, Library policies, Library collections, Nationalism. 


\section{INTRODUCCIÓN}

En la década de 1910 la Comisión Protectora de Bibliotecas Populares de Argentina elaboró una política de expansión del campo bibliotecario denominada Bibliotecas populares elementales. La propuesta era novedosa: por primera vez la entidad estaba facultada para fundar bibliotecas en los barrios de las ciudades y en los pueblos donde creyera necesario hacerlo. El objetivo era consolidar una política cultural de afirmación del sentimiento nacional, contra los dilemas que, en la perspectiva oficial, habían generado la inmigración y las ideologías de izquierda durante las décadas previas al Centenario. Sintéticamente, el proyecto consistió en la formación de una colección más o menos estandarizada de 500 libros que la Comisión Protectora dejaría en manos de una junta directiva local, integrada de manera inicial por el director del colegio y algunos vecinos de la localidad. Estas bibliotecas se instalaron en las escuelas de manera temporaria, a la espera de que alguna asociación civil se hiciera cargo de su administración. Al cumplir con este último paso, abandonarían su carácter de elemental para convertirse en populares. En el transcurso de 1914 a 1921 se distribuyeron 229 colecciones, aunque no todas experimentaron ese cambio de estatuto. Además de la burocracia que exigió la propuesta, de las partidas presupuestarias que insumió y de la lectura de la realidad bibliotecaria que los miembros de la Comisión Protectora debieron realizar (Planas, 2021), la cuestión demandó la producción de criterios para la elección de un conjunto de obras acordes con la idea de argentinidad sostenida por los sectores dirigentes e intelectuales de entresiglos. Las razones que explican la elaboración de estas colecciones y los procedimientos implicados en la selección de las obras constituyen el objeto de estudio del presente artículo.

Cuatro principios generales rigen el análisis. El primero aborda cuestiones metodológicas que conciernen al modo en que fue reconstruido, a partir de diferentes documentos, el catálogo de las bibliotecas elementales. Seguidamente, se analiza el lugar de la Comisión Protectora como productora intelectual de esas colecciones mediante tres aproximaciones yuxtapuestas: por un lado, los alcances y los objetivos trazados para este repertorio con relación a los dilemas sociales, culturales y políticos planteados por la clase dirigente y el campo intelectual durante las primeras décadas del siglo XX; por otro, la funcionalidad de la biblioteca elemental dentro de la estructura más acotada del campo bibliotecario a la que pertenece; por último, los principios conceptuales que, según la entidad, guiaron el trabajo de reunión de las obras. Una vez reconocidos los puntos cardinales que explican la introducción de esta política de expansión bibliotecaria, se estudia el catálogo propiamente dicho. Este tercer movimiento requirió prestar atención a dos series de fenómenos: uno, vinculado a la manera en que la Comisión Protectora completó con títulos específicos esos criterios conceptuales de selección; otro, relacionado con la forma en que la entidad construyó su propia colección a partir de la asimilación o identificación de sus intenciones con aquellas que promovieron algunos editores comerciales a través de sus sellos y bibliotecas. Finalmente, se propone recapitular y evaluar las principales constataciones realizadas, en la búsqueda de problematizar las relaciones entre la constitución de una política bibliotecaria y la formación de una colección de lecturas.

\section{LA RECONSTRUCCIÓN DEL CATÁLOGO}

De los varios expedientes históricos que en la actualidad están disponibles a la consulta en el archivo de la Comisión Nacional de Bibliotecas Populares no fue posible localizar una versión oficial, preliminar o definitiva, del catálogo elaborado para las bibliotecas elementales. Bajo esta circunstancia, el Libro de Actas de la Comisión Protectora brinda información sobre las obras compradas por el organismo, en especial, a partir de la gestión de Miguel Rodríguez. Estas adquisiciones no estaban vinculadas al mecanismo de subvención de la Ley 419, es decir, no corresponde asociarlas a los pedidos formulados por las bibliotecas populares. Este conjunto de libros generalmente fue distribuido entre los establecimientos educativos, principalmente en los colegios nacionales, y en las propias bibliotecas populares, en muchas oportunidades como estímulo al 
inaugurarse la institución. En este contexto, también quedaron anotadas las compras realizadas durante el proceso de selección y constitución de la colección para las bibliotecas elementales y, una vez que fueron formadas, se registró la ciudad, la localidad y/o el barrio de destino. En rigor, esta política implicó dos series de compras. Cuando el proyecto se inició a mitad de 1914 - aunque ya estaba en el horizonte de estrategias del organismo desde 1912, y solo fue demorado por problemas políticos y económicos-, los miembros de la Comisión Protectora consideraron pertinente formar cien bibliotecas. Al cierre de ese año, se agregaron otras diez colecciones, para atender a los barrios periféricos de Rosario —-donde observaron con preocupación el avance de las organizaciones culturales de las izquierdas-. Con todo, esta primera generación de ciento diez bibliotecas concitó la puesta en acto de la selección y la compra del material bibliográfico. Transcurrido el año 1915 y una parte de 1916, y fundadas ya muchas bibliotecas, Rodríguez consideró que era impostergable avanzar con el plan, para lo cual solicitó autorización para formar otras cien colecciones, sobre la base de las listas de libros comprados con anterioridad. Así, la segunda generación de bibliotecas elementales continuó con los parámetros temáticos, estéticos e ideológicos de las primeras compras. Sin embargo, los detalles de las nuevas adquisiciones no se especifican del mismo modo que al inicio, con excepción de algunas colecciones determinadas. Es por esta razón que, a los efectos de procurar tener un control metodológico adecuado en la reconstrucción del catálogo, este estudio se limita al análisis de lo que aquí se denomina primera generación, en alusión a ese primer corpus bien delineado y aprensible.

Cuando se trató de la adquisición de libros, la referencia que apuntó el secretario de actas solo informa el título y el autor del ítem en cuestión. De manera que, para reconstruir la cita ideal, se siguió la metodología propuesta por Alejandro Parada (2005, 2008) para la restitución y el análisis de las listas de librerías históricas, que consiste en rastrear cada ítem en los catálogos de las grandes bibliotecas de mundo y, a partir de ellos, completar la información faltante en el documento original. Dado que la abrumadora mayoría de las obras que se estudian fueron editadas en Argentina o en España, las bibliotecas escogidas para guiar la búsqueda, en el orden que se indican, fueron las siguientes: 1) Biblioteca Nacional Mariano Moreno; 2) Biblioteca Pública de la Universidad Nacional de La Plata; 3) Biblioteca Nacional de Maestras y Maestros; 4) Biblioteca Nacional de España; 5) Biblioteca del Congreso de la Nación Argentina. Cuando estos repositorios no aportaron información alguna, se buscó en Google, que usualmente remitió a sitios de venta de libros antiguos, desde los cuales se restablecieron algunas de las citas.

Las estrategias de búsqueda debieron ajustarse en cada caso y, en general, se procedió desde la aplicación de estrategias de recuperación focalizadas, al emplear protocolos que incluyeron el uso de varios filtros temáticos simultáneos (autor, título, segmentos temporales acotados, etc.), hacia operaciones muy generales, cuando la información disponible en el documento primario era poco clara, confusa o inexacta. Esto sucedió cuando, por ejemplo, el secretario de actas apuntó el título de forma incompleta o bajo una denominación coloquial ("Poesías", de Darío). Diferente fue el caso de la identificación de las obras que la Comisión Protectora compró como parte de una colección editorial (completa o una selección), y cuyo detalle de inventario no aparece en las actas. Para proceder a la reconstrucción, se tomaron las referencias que ofrecen las investigaciones realizadas en el campo de la historia de la edición y, desde luego, las remisiones y los avisos que aparecen en los libros incluidos en esas bibliotecas. Esto resultó particularmente efectivo para los Manuales Soler y los textos de la colección Pureza y Verdad. Un poco arduo fue el rescate de la Biblioteca Rural Argentina, de Ramón A. Lastra, de la que se conoce poco, y cuya recuperación se hizo a través de los catálogos de varias bibliotecas.

Pero sin duda fue la reposición de las obras escogidas de la Biblioteca de La Nación lo que mayor dificultad conllevó porque, para 1914, esta colección tenía más 600 títulos publicados. Como la empresa editaba a razón de 48 volúmenes al año, era probable que la Comisión Protectora se hubiera concentrado en los últimos años hasta completar los 125 libros que adquirió en la primera compra. Pero solo era probable. Todavía más: un anuncio aparecido en La Nación el 3 de enero de 1914 echaba por tierra una suposición de este tipo, al poner en evidencia que los ejemplares a la rústica publicados desde 1901 estaban todos disponibles para la venta. La 
lista de una distribuidora de libros confirmaba el mismo dato (Catálogo de los libros existentes de la Biblioteca de La Nación, 1920). La búsqueda había llegado a un callejón sin salida. Pero una feliz coincidencia hizo que, en noviembre 1914, mientras que la Comisión Protectora aprobaba el envío de una biblioteca elemental a San Roque (Corrientes), unos vecinos de esta localidad iniciaban los trámites para formar una biblioteca popular, sin más libros que una veintena de donaciones. Las dos iniciativas se hicieron una. Y como parte de la burocracia que exigía la Comisión Protectora para reconocer una nueva institución, la junta directiva de la biblioteca de San Roque remitió el inventario de los libros, que ahora estaba integrado mayoritariamente por esa colección elemental (Comisión Protectora, 1914-1915). En la lista estaban los Manuales Soler, la colección Pureza y Verdad, la Biblioteca Rural Argentina y las obras que se habían adquirido de forma independiente. Restaba, entonces, identificar los que correspondían a la Biblioteca de La Nación. Hasta donde fue posible verificar, la situación no se repite de la misma manera en otros expedientes. El hallazgo no solo contribuyó a completar la serie faltante de la Biblioteca de La Nación, sino que facilitó la recuperación de otros libros enviados por la Comisión Protectora, como las publicaciones oficiales, y cuya disponibilidad estaba en los depósitos de la institución.

\section{LOS LIBROS ELEMENTALES, ¿PARA QUÉ?}

Los editores comerciales procuraron, toda vez que lanzaron sus colecciones al mercado de lectores, sellar la coherencia de su producción mediante una declaración de intenciones, esto es, un texto que fija una línea de trabajo, delimita muchas veces un objeto de conocimiento, circunscribe un horizonte de libros venideros, y también convoca a un lectorado (Palierne, 2017). La Comisión Protectora publicó algo cercano a este tipo de ensayos propedéuticos en 1917, en el contexto de la Memoria del organismo correspondiente a 1915 y 1916 y cuando poco más de un centenar de las colecciones elementales habían encontrado un destino. Aquí, como en los manifiestos editoriales, se procuró fijar una identidad, un propósito, un público. Pero, a diferencia de éstos - siempre o casi siempre prospectivos-, se hizo de manera retrospectiva. No se trató de un descuido: es probable que la condición de balance administrativo propiciado por la Memoria haya obligado a la composición de este texto. En cualquier caso, el escrito cumple con varias de las características que reúne una auténtica declaración de intenciones, pero ajustada, como resulta previsible, a los alcances de una política bibliotecaria de lectura.

El análisis puede comenzar por el nombre "Bibliotecas elementales". No se trata, según los miembros de la Comisión Protectora, de un calificativo para identificar a los textos que contiene. Lo elemental es aquí una manera de distinguir el acto fundacional: la biblioteca popular es la que se origina en la sociedad civil, de la mano de un club o de una sociedad de fomento; una biblioteca elemental, en cambio, es la que elige y adquiere el Estado y pone en manos de una asociación. Es, en otras palabras, un conjunto de libros entregados de forma gratuita para incentivar y fomentar el desarrollo de proyectos bibliotecarios. Es elemental en el sentido de primordial, de esencial y primero. Por lo tanto, si bien es un repertorio cerrado, mantiene su significación como proliferación, es decir, se espera que aquellos que se hagan cargo de esta colección la prolonguen con nuevas obras. Es, además, un nombre transitorio: "una vez arraigada la biblioteca [elemental], se convierte en simplemente popular, como las otras, prestando idénticos servicios" (Comisión Protectora, 1917, p. 9). La cuestión del nombre, de su desplazamiento, deja entrever el problema sociocultural que plantea la colección elemental y que, con su constitución, viene a resolver: la escasa iniciativa asociativa que la Comisión Protectora detecta en muchos pueblos y ciudades del país. Pero no solo es un asunto que remite a la actividad asociacionista; involucra una cuestión mucho más amplia, dentro de la cual el organismo propone una respuesta en el marco de sus competencias: la conservación de la cultura nacional frente al dilema político y social producido por la inmigración. Así se expresa el tema en la declaración de intenciones:

Muchas de estas bibliotecas [elementales] se han fundado en los Territorios Nacionales, los que tenían muy pocas populares, persiguiéndose, no sólo la difusión de conocimientos, sino otro propósito superior: defender nuestras fronteras de la lenta 
penetración de elementos extraños, portadores de sentimientos y modalidades no siempre armónicos con el interés de la nacionalidad. A estas bibliotecas se ha enviado, con ese propósito, libros de historia y geografía argentinas, para intensificar, en lo posible, el sentimiento de la patria (Comisión Protectora, 1917, p. 9).

Los problemas que la colección elemental se propone resolver parecen demasiado complejos para la eficacia de una modesta reunión de libros. Pero la Comisión Protectora no fue la única lanzada en el espacio público a la conquista de la nacionalidad, aunque sí representaba la única alternativa bibliotecaria diseñada desde el Estado nacional para captar un lectorado amplio. Los argumentos precedentes constituyen una síntesis de la construcción conceptual que sus miembros también expusieron en otras publicaciones y en las reuniones de comisión que mantuvieron en el ámbito privado (Planas, 2019, 2021). En todo caso, la entidad expresó una preocupación del campo intelectual y del campo político progresivamente intensa desde el final del siglo XIX y la volcó sobre otro campo, el bibliotecario. Como se sabe, el lugar que había ocupado la inmigración en el proceso de modernización social que propuso la generación de 1937 se resquebrajó conforme se percibieron las primeras y evidentes objetivaciones en el transcurso de la década de 1880. La desconfianza no alcanzó al punto de restringir la llegada de barcos al puerto, pero sí se tradujo, por una parte, en una apabullante literatura sobre el tema y, por otra, en una definición más precisa de las instituciones encargadas de reforzar los vínculos de la comunidad nacional que esa literatura veía difuminarse en el complejo y heterogéneo tejido social. Terciaba entre esos polos una política represiva contra la organización del movimiento obrero. Después de todo, la cuestión de lo extranjero como elemento disolvente de las tradiciones no remitía solo al número y a la convivencia de múltiples maneras de habitar el espacio urbano, sino más bien a la introducción de la idea de lucha de clases que aportaron las vanguardias militantes de las izquierdas al cuadro político de la Argentina, y que con anterioridad estaba ausente de forma explícita (Halperín Donghi, 2017). La Ley de Residencia de 1902 y la Ley de Defensa Social de 1910 constituyen, en este sentido, expresiones legitimadas de la coerción ejercida sobre la protesta social. Un sistema coercitivo que, sin embargo, no era suficiente para contener la demanda de ampliación democrática que se levantaba sobre un régimen oligárquico en plena descomposición en el novecientos. La amalgama de esta serie de elementos, que se recortan a su tiempo en un contexto internacional de abiertas hostilidades entre las naciones, requirió también tensar las cuerdas consensuales y del adoctrinamiento ideológico. La escuela, desde luego, fue la base institucional predilecta de la dirigencia conservadora primero, y del radicalismo después, para sedimentar en los hijos de inmigrantes el conocimiento de la argentinidad (Bertoni, 2001). Ahora bien, mientras que las recomendaciones para crear o reencauzar la tradición que Ricardo Rojas se permitió formular en La restauración nacionalista (1910) eran potencialmente realizables dada la existencia de un sistema educativo extenso y consolidado, la Comisión Protectora de Bibliotecas Populares, en cambio, solo tenía tras de sí tres largas décadas de ausencia estatal en materia de políticas bibliotecarias de lectura.

Todavía más: cuando en 1912 los miembros de la entidad comenzaron a recortar la forma que iba a tomar su biblioteca elemental para cumplir con el objetivo de contribuir a la nacionalización de las masas, lo hicieron a sabiendas de que el ámbito en el que les tocaba participar era muy competitivo. Fueron, en este contexto, las formaciones políticas y culturales de las izquierdas las que se presentaban como rivales de fuste en cuanto a los circuitos de circulación de los libros, tanto en el campo de la edición como en el bibliotecario. Por el lado de la cultura socialista, si a mediados de la década de 1895, cuando el partido estaba en pleno proceso de formación, se editaban mil ejemplares de una obra, diez años después el mismo título admitía una tirada de cinco mil. Como analizó Horacio Tarcus (2013), el vertiginoso aumento del lectorado socialista se comprende, en parte, por la agresiva estrategia de publicación de periódicos y folletos que de forma progresiva construyó el partido y, también, por las diversas modalidades de circulación sobre las cuales apoyó y reforzó la difusión de esa palabra escrita: circuitos de venta estables y ambulantes, clubes de lecturas, conferencias y bibliotecas. Estas últimas alcanzaron un desarrollo notable. Según Ángel Giménez — uno de los dirigentes más importantes de la época-, para 1918 el partido contaba con 132 establecimientos organizados y unos 66 en formación. La mayor parte se encontraban en Capital Federal y provincia de Buenos Aires, pero la progresión en el 
interior auguraba un futuro promisorio. Cuando el propio Giménez actualizó los datos para la publicación de Nuestras Bibliotecas Obreras (1932), el total de instituciones en 1932 ascendía a 397, destacándose el crecimiento en provincias como Mendoza, Santa Fe, La Pampa, Tucumán y Entre Ríos.

El socialismo tenía, en los contornos amplios del campo de las izquierdas, su propio y tenaz competidor: el anarquismo. En cuestión de ediciones, ambos compartieron la necesidad de editar sus libros y folletos, esfuerzo que no solo realizaban por la confianza que depositaron en la lectura como práctica de transformación cultural, sino también porque, operativamente, no había en los circuitos tradicionales de la Argentina imprentas que publicaran sus colecciones ni librerías que importaran su literatura. Para Juan Suriano (2008), estimar el volumen de los impresos libertarios que circularon entre 1890 y 1910 es una tarea compleja, debido a la ausencia de documentos en los que se pueda constatar las tiradas y las ventas. No obstante, el autor supone una producción probable de siete u ocho títulos en un año regular, que en conjunto pudieron sumar 20,30 o 40 mil ejemplares —cifra nada desdeñable, según su perspectiva, al considerar la aridez de la prosa doctrinal-. A esa proliferación libresca debe consignarse, además, la relevancia que adquirieron los diarios y los periódicos, por una parte, y, por otra, el dispositivo de difusión que, al igual que los socialistas, los anarquistas también construyeron sobre la base de conferencias, círculos de lectura y bibliotecas. En este último caso, resulta difícil identificar el concepto de biblioteca ácrata con el que sostuvo el socialismo o con el que propició la Comisión Protectora. Como señaló Mariana di Stefano (2013), la precariedad económica y la persecución policial que padeció el anarquismo dificultaron la preservación y el sostenimiento de los locales. De manera que la reunión de libros, el orden, el flujo de lectores, la apertura pública con regularidad y, en fin, los elementos habitualmente asociados a las bibliotecas, en el sentido institucional, quedaron muchas veces a distancia de la realidad. Esto no impidió que durante la primera década del novecientos se crearan espacios para la lectura, más o menos estables, más o menos móviles. Mediante un relevamiento de notas en La Protesta (Humana), Eugenia Sik (2018) registró al menos 46 menciones que refieren a la creación de una biblioteca en los años de apogeo del anarquismo (1898-1905), en general radicadas en Capital Federal y otros centros urbanos de importancia, como La Plata y Rosario.

El progreso de esas ediciones de libros, folletos y periódicos, y, en particular, la proliferación de las bibliotecas obreras entre el final del siglo XIX y la primera década del XX propició, entonces, la restitución de la Ley 419 de fomento a las bibliotecas populares y el restablecimiento de la Comisión Protectora en 1908, mediante un decreto reglamentario que ampliaba las funciones de la entidad con relación a su predecesora de 1870 (Planas, 2017). El mensaje oficial que acompañó y justificó el nuevo dispositivo legislativo era explícito en cuanto al problema que se deseaba atender: "existen en el país asociaciones que propagan doctrinas contrarias al mantenimiento de la organización actual del Estado perturbando el criterio popular en forma alarmante (...). [Estas] asociaciones se han apercibido de que las bibliotecas populares constituyen el mejor vehículo para la propagación de sus ideas (...)" (Ministerio de Justicia e Instrucción Pública, 1908, p. 15). Si bien durante los primeros años los recursos dispensados para esta estrategia no parecen haber sido acordes con las dramáticas dimensiones que en el discurso le fue atribuida a la cuestión, lo cierto es que las bibliotecas respaldadas por el Estado crecieron cuantitativamente año tras año: en el Centenario existían 191 bibliotecas populares; en 1911, 210; en 1912, 223; en 1913, 226; en 1915, 366 populares y 67 elementales; $^{1}$ mientras que en 1916 las primeras ascendían a 400 y las segundas a 122 . Como se observa en esta progresión, la introducción de las bibliotecas elementales constituyó una herramienta para expandir el campo bibliotecario de acuerdo con los lineamientos fijados en 1908. Ahora bien, la política general que fijó la Comisión Protectora no trató de la misma manera a todas las bibliotecas de carácter obrero (Tripaldi, 1997). Las que organizaron las agrupaciones anarquistas, ya muy menguadas por la tenacidad de la represión policial y la deportación de muchos de sus militantes, quedaron en términos generales al margen de las subvenciones ofrecidas, que por otra parte es poco probable que hubieran deseado usufructuar por la idiosincrasia propia del movimiento. Por su parte, los socialistas recurrieron a partir de 1910 a estos fondos para sostener sus bibliotecas. Esta convivencia no siempre fue fácil, aunque hay indicios que muestran que la 
Comisión Protectora estaba más preocupada por el cumplimiento de los horarios de apertura y cierto orden institucional que por el tipo de lecturas que cada biblioteca fomentaba (Fiebelkorn, 2018).

La multiplicación de bibliotecas dispuestas a competir por el lectorado, con recursos dispares y tradiciones diferentes, produjo un efecto dóxico en el campo bibliotecario, esto es, de izquierda a derecha del arco ideológico las propuestas encontraron como fundamento de su sentido político la necesidad de acompañar la formación de los lectores y las lectoras mediante series de libros selectas y organizadas, frente a la alternativa extensa y poliforme que ofrecía el mercado de impresos al inaugurarse el siglo XX. Como quedó dicho, las izquierdas produjeron sus propias publicaciones y circuitos de venta, mientras que la Comisión Protectora debió recortar su interés dentro de lo que estaba a disposición en el comercio. Para ese entonces, la actividad editorial estaba constituida por un segmento de folletines, compuesto principalmente de literatura criollista y de novelas sentimentales (Adamovsky, 2019; Sarlo, 1985), y otro relacionado con la producción y la puesta en circulación a bajo costo de libros considerados de calidad — en términos materiales y literarios-, reunidos bajo un lema o marca, y cuyo prestigio quedaba asociado a la figura de un intelectual o editor responsable de su cuidado (Merbilhaá, 2006). Nada de lo que remite al primero de los segmentos fue considerado una opción para la Comisión Protectora, que fijó su horizonte de lecturas para las bibliotecas elementales dentro de los límites del segundo grupo, conforme los criterios siguientes:

Las colecciones de libros que se remiten, no son propiamente de obras selectas, en un sentido estricto, porque esta Comisión ha tenido que y tiene que aprovechar los elementos de que dispone, y, además, porque cuenta con limitados recursos; pero, sin abandonar la base de los libros de literatura y de historia, que son los más comúnes y baratos, matiza las colecciones con obras referentes a nuestras industrias madres - ganadería y agricultura - y libros elementales de ciencias y de ciencias aplicadas. Toda obra útil que se publica en nuestro país o en el extranjero, y que es de precio moderado, es adquirida por esta Comisión para dichas bibliotecas, tratando de fomentar la aficción a los libros de estudios prácticos o que tiendan a formar el carácter y la voluntad (Comisión Protectora, 1917, p. 7).

La idea de intensificar el sentimiento de argentinidad que la Comisión Protectora se fijaba como prioridad debió construirse sobre la cuestión más obvia y perentoria de formar una colección para una biblioteca, es decir, un repertorio que contenga una diversidad de obras capaz de brindar respuesta a un número amplio de inquietudes, ya sean recreativas o técnicas, de referencia o instrucción. El kit temático, en este contexto, debía rebasar la búsqueda de lo nacional que los emprendimientos editoriales contemporáneos como "Biblioteca Argentina”, de Ricardo Rojas, o "Cultura Argentina”, de José Ingenieros, buscaron de forma alternativa en las letras o las ciencias sociales, respectivamente (Degiovanni, 2007). La biblioteca elemental, en este sentido, fundía y filtraba los campos del saber que de forma progresiva se especializaba en favor de la elaboración de una metodología de selección y producción orgánica y coherente de la colección. Los libros escogidos, como se aprecia en la cita precedente, remiten a dos criterios que, en el concepto sostenido en la declaración de intenciones por la Comisión Protectora, conforman un saber que complementaba la "faz práctica de la vida" y "el factor moral e intelectual". Una cuestión y otra eran percibidas como necesarias para el desarrollo de una nación moderna, y para evitar que en el futuro el pueblo argentino se transforme en un "organismo anormal e incompleto", una analogía biologicista típica de la época, y que en este contexto sugiere que los libros escogidos forman parte de una prescripción médica.

Los principios enunciados, junto con la economía del lenguaje de los que están hechos, testifican la manera en que los problemas intelectuales y políticos se introducen en el campo bibliotecario y se especifican como una tecnología. Esos mismos principios creativos debían cubrir, en su forma definitiva como serie ordenada de obras, la demanda de identidad planteada en el Centenario (Terán, 2000). Como dispositivo territorial, las bibliotecas elementales se extendieron por los pueblos del interior del país donde la Comisión Protectora detectó la ausencia de instituciones bibliotecarias, pero también alcanzaron a los barrios obreros de las ciudades más populosas. La sola presencia de estos repertorios informa de la disposición estatal para crear los artificios necesarios para suturar los dilemas derivados de la anomia social y afrontar la formación de ciudadanos integrados a la política democrática inaugurada tras las Ley Sáenz Peña de voto universal, secreto 
y obligatorio con la que se abrió la segunda década del siglo XX. Ahora bien, la especificidad de los símbolos identitarios, sociales y, en general, la representación cultural que la Comisión Protectora buscó transferir con esas bibliotecas elementales requiere abandonar el plano de las declaraciones y pasar al examen de los libros.

\section{EL REPERTORIO ELEMENTAL}

La Comisión Protectora invirtió $\$ 500$ por cada colección. Con este importe se esperaba adquirir 350 obras, que constituirían algo así como el núcleo básico del repertorio. Luego, con los libros que hubiera en existencia en el depósito de la entidad se procuraría completar ese lote y alcanzar un total de 500 libros. Como se deduce, estas colecciones no eran exactamente idénticas unas de otras. En términos cuantitativos, si se sigue la Memoria publicada en 1917 se puede apreciar, por ejemplo, que durante 1915 algunas bibliotecas fueron entregadas con 358 volúmenes y otras con 591. No hay una razón explícita que explique la diferencia dentro de la documentación escrutada para este estudio. Probablemente, la divergencia obedezca a la disponibilidad de ejemplares que se encontraban en un momento u otro en el depósito, aspecto que, por otra parte, estaba relacionado con las cuotas del presupuesto que recibía la entidad. En términos cualitativos no hubo diferencia de criterio que distinga las sucesivas compras, aunque sí se detectan dos modalidades de procesar las incorporaciones. La primera remite a la adquisición de colecciones editoriales completas, como en el caso de los Manuales Soler, o fragmentarias, como sucede con las publicaciones de la Biblioteca de La Nación. La segunda forma parte de las obras que los miembros de la Comisión Protectora escogieron de manera individualizada en el circuito de librerías e imprentas, y que a su juicio complementaba la oferta de esas bibliotecas de editoriales.

A mitad de 1912, al poco tiempo de haberse iniciado la gestión de Rodríguez, se sucedieron en el ámbito de las reuniones de comisión algunas charlas sobre libros. Es posible que estas cuestiones hayan suscitado mayores comentarios de los que fueron registrados en el Libro de Actas: son escasos los juicios valorativos que se encuentran. Cuando los hay, aparecen en las primeras reuniones, donde todo constituye una novedad; con posterioridad, y posiblemente debido al aumento sustancial de los títulos que fueron adquiridos, las noticias sobre estos asuntos se pierden de forma definitiva. Una de esas excepciones está representada por el análisis de los diccionarios enciclopédicos que le fue encargado a Rafael Obligado, con la idea de dotar a las bibliotecas elementales de una fuente de referencia. Concretamente, se ocupó de la obra Pallas: diccionario enciclopédico manual en cinco idiomas: español, francés, inglés, alemán e italiano. El criterio de evaluación comprendió el manejo global de la obra, la correspondencia entre el contenido anunciado y el incluido, la calidad de los artículos y la relación de estas variables con el precio final. El resultado fue el siguiente: “...no es un Diccionario Enciclopédico en cinco idiomas [...], pues no tiene, en realidad, las equivalencias que dice. [...] Su manejo es incómodo, por la forma en la que se ha dividido [...]. Contiene datos inexactos y el precio es muy alto" (Comisión Protectora,1908-192?, Acta 30, p. 25, 10 de Octubre de 1912). Según Obligado, dentro del segmento había otros dos diccionarios enciclopédicos superiores. Se trataba del Campano ilustrado, diccionario castellano enciclopédico, de Manuel González de la Rosa, en la edición parisina de Garnier de 1908, y del Nuevo diccionario enciclopédico ilustrado de la lengua castellana, de Miguel de Toro y Gómez, publicado en París en 1908 por Colin. Entre esas dos alternativas, finalmente se adquirieron 100 ejemplares del Campano Ilustrado. Pero esta no es, sin embargo, la única obra de referencia adquirida por la Comisión Protectora. Con toda probabilidad, según se recoge del inventario de la Biblioteca Popular San Martín de San Roque, fueron incorporadas otras seis fuentes a las colecciones elementales: dos de la lengua: Diccionario de la Lengua Castellana y Gramática de la lengua castellana, ambos publicados por la Real Academia Española en 1914 y 1913, respectivamente; tres diccionarios bilingües: dos ediciones de Garnier: Nuevo diccionario francés-español y español-francés, de Vicente Salvá (1889), y el Diccionario inglésespañol y español-inglés, de Francisco Corona Bustamante (1902); un Diccionario italiano español y español italiano, del que no se pudo determinar la edición. Finalmente, la Nueva enciclopedia de conocimientos útiles. 
Para saberlo todo, Para recordarlo todo, publicada por los Hijos de Santiago Rodríguez en 1912. En conjunto, y dadas las características de los títulos, se puede afirmar que, mediante una inversión relativamente modesta, los miembros de la Comisión Protectora dotaron a las bibliotecas elementales del ABC de la consulta de referencia, un segmento de la colección que, sin perjuicio de otros usos y otros públicos, estaba destinado especialmente a zanjar las dudas de los escolares.

Los diccionarios y las enciclopedias constituyen la entrada a la biblioteca. El resto de los anaqueles se llena con los libros que, según quedó dicho, forman la "faz práctica de la vida", de un lado, y el "factor moral e intelectual", de otro. Sobre este último criterio, la Comisión Protectora adquirió varias colecciones de la Biblioteca de La Nación. En agosto de 1914, para la primera generación de bibliotecas elementales, se invirtieron $\$ 65$ por cada una de las 100 colecciones de alrededor de 125 títulos (12.500 ejemplares, aprox.). Otras seis veces se le compraron al diario paquetes de libros, y siempre se pagó \$95 por cada colección de 200 ejemplares: en agosto de 1916, 25 colecciones, y en diciembre de ese mismo año otro lote idéntico; en abril de 1917 fueron 95 colecciones, mientras que en agosto unas 25 más; finalmente, en diciembre de 1918 se aprobaron dos compras de 25 colecciones cada una. Al término del período 1914-1918 se adquirieron bajo esta modalidad unos 56.500 ejemplares en rústica. Los cuatro años que separan la primera compra de la última informan, además, sobre las eventuales discrepancias en los títulos que integraron cada uno de eso repertorios, sujetos a la disponibilidad de existencias o a otros criterios difícilmente constatables. Por ejemplo, la reconstrucción del catálogo de la Biblioteca Popular San Martín mostró que ninguno de los títulos enviados representaba, en sentido estricto, una novedad: todos los libros habían aparecido entre 1901 y 1911 , aun cuando la Comisión Protectora los adquirió en 1914. Esto no significa, sin embargo, que habían perdido actualidad literaria. Como sostuvo Merbilhaá (2006), la noción de lo nuevo constituyó uno de los criterios que fundaron el proyecto editorial del diario, junto con una idea de calidad material y de contenido selecto; todos elementos constitutivos que se mantuvieron constantes a lo largo de casi dos décadas y más de 800 títulos publicados, si bien algunas obras del catálogo consideradas de menor prestigio obligan a matizar esta perspectiva general. La cuestión, ahora, es identificar qué era aquello que la Comisión Protectora buscó con esta selección de literatura organizada por Roberto Payró y sus continuadores.

Entre los editores de la Biblioteca de La Nación y los miembros de la Comisión Protectora se extiende un imaginario sincrético que ambos expresaron a través de las declaraciones de intenciones y de los objetivos con los que dotaron el desarrollo de sus proyectos. La bibliografía que estudió la colección, desde Rivera (1980) a Rodríguez Giavarini (2018), pasando por De Sagastizábal (1995), Severino (1996), Wilson (2004) y Merbilhaá (2006), destaca el carácter pedagógico de esta empresa editorial que, por una parte, se propuso guiar o auxiliar las lecturas populares al ofrecer una serie ordenada de literatura de cierta complejidad narrativa y, por otra, desplazar de los gustos del lectorado nacional la parafernalia criollista formada en las últimas décadas del siglo XIX. Si el éxito de los géneros seleccionados - la novela policial, sentimental, fantástica, histórica o de aventuras - se debió en buena medida a su inserción en los hábitos culturales y de consumo que los lectores y las lectoras se habían formado en los folletines; el libro en sí mismo, con el cuidado material y de diseño con el que fue concebido, ponía por primera vez en manos de ese público un objeto de prestigio coleccionable (Rodríguez Giavarini, 2018). Una dimensión y otra — simbólica y material - reforzaban la mentalidad pequeño-burguesa que llevaba inscripta la Biblioteca de La Nación. Y ninguno de estos elementos era ajeno a las finalidades de la Comisión Protectora. En primer lugar, los resultados comerciales que la colección obtuvo desde su lanzamiento en 1901 le entregaban garantías a la entidad de la potencial acogida que esos mismos libros podían tener entre los lectores de las bibliotecas elementales. En segundo término, las bibliotecas populares formadas en Argentina desde 1870 habían llenado sus estantes con aquel fondo cultural aportado por los folletines franceses y españoles, de manera que las condiciones de posibilidad para acumular una nueva y moderna literatura estaban dadas. Esas mismas bibliotecas populares que, por otro lado, se mantuvieron al margen del fenómeno editorial que significó - y que significaría durante algunas décadas más- el criollismo. De este modo, la Comisión Protectora no solo construyó su colección 
literaria en base a sus creencias y afinidades estéticas e ideológicas, sino que además lo hizo sobre una tradición bibliotecaria de la que debió que dar cuenta y en la que se respaldó.

Al examinar los 125 títulos de la Biblioteca de La Nación que fueron incorporados a la primera colección elemental se aprecia una representación a escala de la variedad de géneros y autores extranjeros que hasta 1911 fueron publicados. Si se retoma la clasificación propuesta por Wilson (2004), se puede encontrar como ejemplo: (a) entre los románticos, Chateaubriand (Atala ; René ; El último abencerraje), Víctor Hugo (Noventa y tres) y Lamartine (Graziella, Rafael, El manuscrito de mi madre); (b) entre los realistas y naturalistas, Balzac (Eugenia Grandet, El lirio en el valle, El martirio de un genio); (c) el género policial es, sin duda, el más nutrido: la lista la encabeza Doyle con diez títulos (La señal de los cuatro, Las hazañas del Brigadier Gerard, Nuevas hazañas de Sherlock Holmes, Triunfos de Sherlock Holmes, Nuevos triunfos de Sherlock Holmes, La resurrección de Sherlock Holmes, La mancha de sangre, La viuda seria, Casos secretos de Sherlock Holmes, Sir Nigel), y bastante más atrás siguen Poe (Historias extraordinarias, Aventuras de Arturo Gordon Pym) y Conway (Misterio...: (called back), Confusión); (d) en ciencia ficción, Wells (Una bistoria de los tiempos venideros); (e) entre los rusos, Tolstoi (Resurrección), Dostoievski (El sueño del Tío) y Turgenev (Aguasprimaverales); de los folletinistas franceses, Dumas padre se lleva ocho títulos, algunos en varios tomos (Los tres Mosqueteros, Actea, Los compañeros de Jehú, La boca del infierno, Olimpia, El Conde de Montecristo, La mano del muerto, Amaury); finalmente, entre los norteamericanos, Harte (Bocetos californianos). A esta lista puede agregarse la presencia del italiano Edmondo De Amicis con dos obras (Corazón; La maestrita de los obreros). Dentro de esta genealogía, la Comisión Protectora incorporó por su cuenta a la colección elemental unos pocos autores que también fueron publicados por La Nación, pero que no entraron en esta compra: Scott (Ivanhoe: ó el cruzado), Flaubert (Salambó) y Cooper (Los puritanos de América o El valle de Wish-tonWish). Fuera de ese canon, pero dentro de los amplios límites de las lenguas extranjeras, se adquirieron las obras de dos autores de autoayuda: el norteamericano Orison Swett Marden, (Abrirse paso, La alegría del vivir, Siempre adelante) y el escocés Samuel Smiles (;Ayúdate!; El ahorro; El deber; El carácter; Los dos césares: romance histórico-religioso).

De la lengua castellana, la Comisión Protectora tomó el libro lanzamiento de la Biblioteca de La Nación: Tres novelas picarescas, que compilaba en un volumen una obra de cada uno de los siguientes clásicos: Cervantes (Rinconete y Cortadillo), Quevedo (La historia y vida del gran tacaño) y Hurtado de Mendoza (La vida de Lazarillo de Tormes y sus fortunas y adversidades). En esta línea también se incluyó El Quijote. Fuera de este canon, apenas fueron agregadas dos obras de autores españoles: una del célebre folletinista Fernández y González, y otra del escritor realista Pedro Antonio de Alarcón. Entre los latinoamericanos, solo Isaacs, con María. Y apenas cinco autores nacionales: Mitre (Historia de San Martín y Arengas de Mitre); Sarmiento (Facundo y Recuerdos de Provincia); Daireaux (Las veladas del tropero); Bunge (La novela de la Sangre) y Podestá (Alma de niña). Para completar la nómina de literatura correspondiente a la lengua, la Comisión Protectora debió abrirse al mercado de librería. En algunas ocasiones encargó expresamente los títulos, y en otras oportunidades seleccionó de acuerdo con los ofrecimientos que los libreros le hacían llegar. Así, por ejemplo, la nómina de españoles se reforzó con Espronceda (Obraspoéticas), Pérez Galdós (Halma y Marianela), Blasco Ibáñez (La catedral: novela; Los muertos mandan: novela), Palacio Valdéz (Aguas fuertes) y Valle Inclán (Cuentos de abril). La lista de los nacionales resulta llamativamente escasa, si se la contrasta con la inflexión nacionalista del discurso que sostuvo: Oyuela (Canto a la patria), del Campo (Fausto), Guido y Spano (Poesias completas); Hernández (Martín Fierro); Mármol (Obras poéticas y dramáticas) y Elflein (Del pasado y Leyendas argentinas).

Pero más que literatura nacional, los miembros de la Comisión Protectora optaron por engrosar el catálogo de las bibliotecas elementales con ensayos de interpretación de la realidad argentina y con obras que cubrieran las necesidades del currículum escolar. Es por esta vía que le dieron representación tangible a esa idea de intensificar el sentimiento hacia la patria. No era una propuesta innovadora ni mucho menos: el entresiglos estuvo bien cargado de estudios de carácter social, histórico y literario que, en conjunto, propiciaron la 
emergencia del campo intelectual, con sus escritores nóveles y consagrados, con renovadas instituciones e instancias de reconocimientos, con un núcleo de temas que giró sobre la tradición, la raza, la nación, la cohesión social y la representación política (Altamirano y Sarlo, 2016), y que también contó con formas sustancialmente nuevas de producir enunciados, entre las que se destacó la apelación a la ciencia como dadora de legitimidad (Terán, 2000). Entre los escritores que alcanzaron trascendencia, en el catálogo aparece Joaquín V. González (La tradición nacional, Mis montañas, Patria y Manual de la Constitución Argentina), Manuel Gálvez (El solar de la raza), Carlos Octavio Bunge (Nuestra América), Agustín Álvarez (La transformación de las razas en América), Leopoldo Lugones (Elogio de Ameghino y El imperio jesuitico), Ricardo Rojas (Blasón de plata) y Manuel Ugarte (La joven literatura hispanoamericana), entre otros. Junto a estos autores contemporáneos a la gestión de la Comisión Protectora, se agregaron algunos clásicos del siglo XIX que habían quedado fuera de la selección provista por la Biblioteca de La Nación: Alberdi (Bases y El crimen de Guerra), Vicente Fidel López (La gran semana de 1810 y Manual de historia argentina) y Martín García Mérou (Historia de la República Argentina). No se puede inferir de esta nómina, ni aún si se incorporaran los títulos que en lo sucesivo fueron adquiridos, que los miembros de la entidad hayan alentado una tendencia explicativa específica o única respecto de la realidad social. Lo que es claro - y esto es lo que interesa-, es que el recorte interpretativo fue realizado desde la matriz propiciada por la cultura intelectual dominante. Después de todo, la Comisión Protectora era una de esas instituciones estatales desde donde era posible instrumentar algunas de las esperanzas que esos intelectuales sostenían sobre los procesos de instrucción como dispositivos de transformación cultural y nacionalización —en ocasiones, como observó Terán (2000) sobre Bunge, en forma de consuelo respecto de las limitaciones de la raza-.

Coherente con lo manifestado en la declaración de intenciones, la Comisión Protectora incorporó estudios sociales, de historia y geografía en la elaboración del repertorio escolar. En cuanto a las dos primeras materias, además de los textos sobre historia europea antigua, medieval y moderna, y de los ya citados ensayos de Mitre y López, fueron agregados autores nacionales como Rivarola (Fernando en el colegio), Álvarez (Estudio sobre las guerras civiles argentinas), Imhoff (La historia argentina en cuadros para los niños), Levene (Lecciones de historia argentina) y Scotto (Efemérides de la República Argentina). En geografía también se tuvieron en cuenta obras generales, como la de Reyna (Geografía Universa), y trabajos de carácter local, como el de Urien y Colombo (Geografia general de la República Argentina), seleccionado en ese entonces por el Ministerio de Instrucción Pública como saber geográfico oficial. Las restantes asignaturas del currículum se completaron con títulos escogidos de series editoriales más amplias. Entre las disciplinas exactas y naturales, fueron recogidos varios libros de la colección Cartillas Científicas o Nuevas Cartillas Científicas, de la empresa norteamericana Appleton (Nociones de botánica, Nociones de fisiología, Nociones de física, Nociones de quimica, etc.). Para el segmento dedicado a las artes, se tomaron cuatro obras de la Biblioteca Popular de Arte de la editorial La España de Madrid: El arte en la Antigüedad, El arte en la Edad Media, El arte en la Edad Moderna y El arte en el siglo XIX. Pero la colección editorial que sí tiene un papel preponderante en el contexto de las obras escogidas para este ramo es: Escuela Moderna: serie elemental de instrucción primaria, editada por Cabaut durante el primer tercio del siglo XX. Se trata de una biblioteca de libros de textos, de entre 50 y 70 páginas, que cubren todas las materias afines a la educación inicial. Refuerzan y cierran la parte de la biblioteca elemental dedicada a los textos de instrucción algunas publicaciones oficiales, entre las que se destacan distintas colecciones de leyes, decretos y códigos de la Argentina, y el Boletín de Instrucción Pública del Ministerio.

Para concluir con aquellos títulos, temas y autores que se derivan del criterio "moral e intelectual”, pero más del lado de la primera pauta que de la segunda — si cabe la distinción —, fueron adquiridas una buena cantidad de obras sobre higiene. Aquí, como en otros puntos, no hay ninguna sorpresa: el entresiglos vio proliferar una abundante literatura de divulgación sobre educación sexual, casi siempre recubierta por una gruesa capa de argumentos médicos que, coincidente con las miradas biologicistas de la sociedad, procuraban apuntalar las normas sexuales tradicionales. De los varios repertorios que por entonces circulaban en España (Guereña, 
2017), la Comisión Protectora adquirió 110 colecciones de los 8 volúmenes que componían la biblioteca Pureza y Verdad, de la editorial Bailly-Baillière, por un total de \$1.476. Los textos se habían publicado originariamente en Estados Unidos y sus autores eran de clara filiación protestante, lo que concitó más de una polémica en las revistas católicas españolas de la época (Seoane Cegarra, 2015). Los títulos conformaban, en conjunto, un mismo conocimiento dosificado por edades y administrado por género. Así, la serie Lo que debe saber la niña, Lo que debe saber la joven, Lo que debe saber la recién casada y Lo que debe saber la mujer a los 45 años era acompañada por otra cadena idéntica, pero destinada al hombre. Además de esta colección, la Comisión Protectora consideró adecuado gastar un poco más de lo ya invertido para sumar otras obras del ramo, pero orientada a la administración de la casa, la conducta y las buenas costumbres del trato social. Entre los títulos, cabe consignar: Gobierno, administración e higiene del hogar; El libro de las madres: manual práctico de higiene; Recetario doméstico: enciclopedia de las familias...; La mujer en el hogar; La botica en casa; Degeneración social y alcoholismo; Manual de urbanidad y buenas maneras.

A mitad de camino entre el criterio que brinda sentido a las elecciones que conforman la parte de la biblioteca descripta hasta aquí, y aquel que rige ese otro conjunto de conocimientos que la Comisión Protectora identificó para la "faz práctica de la vida", se ubica la compra de 110 colecciones a $\$ 75$ cada una de los Manuales Soler. Se trata de una enciclopedia de asuntos variados: historia, ciencia, saberes técnicos y artes y oficio, aunque un repaso por los títulos de los primeros 100 volúmenes del repertorio, que fueron los que adquirió la Comisión Protectora en 1914, informa que el contenido declina sobre las tres últimas temáticas. Según la descripción realizada por Sánchez Vigil y Olivera Zaldua (2014), estos manuales de difusión popular constituyeron la colección emblemática de la editorial Manuel Soler, distinguibles por su formato reducido ( $11 \times 16 \mathrm{~cm}$.), la encuadernación anaranjada y el mueble contenedor de madera que la empresa regalaba a sus suscriptores. En la última década del siglo XIX la empresa y todo su fondo pasaron a manos del sello Gallach, de manera que la colección también fue conocida en adelante como Manuales Gallach, pero distinguibles de aquellos por su nueva cubierta en tela verde. Las monografías iniciales continuaron siendo la base de esta enciclopedia, que solo fue incrementada de forma muy paulatina en relación con el crecimiento de sus primeros años. Las dos modalidades convivieron durante algún tiempo en las librerías. En varios de sus volúmenes, como es habitual para este tipo de series, puede recogerse la lista de obras publicadas y en preparación, además de la declaración de intenciones y, en este caso, una peculiar forma de publicidad que destacaba las ventas de la colección en toda Hispanoamérica mediante gráficos comparativos, aunque los datos son bastante dudosos. Con varios lemas referidos a la instrucción, la libertad y el progreso de los pueblos, los editores presentaron sus manuales como un repertorio moderno, orientado a fomentar las bibliotecas en los hogares de abogados, médicos, agricultores, industriales y comerciantes, pero también para el "obrero estudioso". El traspaso del prestigio simbólico era evidente. Y como en el caso de la Biblioteca de La Nación, los editores también insistieron en la materialidad de los libros y en su sentido como objeto coleccionable, una estrategia que buscaba despertar los sentimientos aspiracionales de los lectores y las lectoras del novecientos. Pero más que la materialidad, la Comisión Protectora vio un corpus coherente de conocimientos prácticos y accesibles económicamente que le permitían obviar esa penosa tarea que suponía escrutar distintos catálogos para escoger título por título las obras consideradas adecuadas. En este contexto de necesidades, el sello Gallach construyó un dispositivo publicitario para dotar de prestigio a su colección y, así, seducir a sus potenciales compradores. El volumen que marca la segunda época de los manuales, La Guinea Española (Beltrán y Rózpide, 1904), es un testimonio tangible. Además de una nota explicativa a cargo del editor con las modificaciones que se esperaban con relación a los futuros títulos y a las mejoras en los ya publicados, las paginas finales (¡más de 50!) subrayan una y otra vez el cuidado puesto en la elección de los libros: 19 firmas entre catedráticos, miembros de la Real Académica Española, ministros de educación y políticos avalaban con sus comentarios el contenido de la biblioteca. Entre ellos, el argentino Estanislao Zeballos consideraba que la colección era “...de la mayor importancia para la educación del pueblo [...]. Los Manuales-Gallach están 
autorizados por firmas de primer orden, y si he de juzgar, por algunos que he revisado, tienen una síntesis de las materias al día" (Zeballos, 1904, p. 253).

Actual, accesible y de calidad, de "utilidad, belleza y economía", como sintetizaban los propios editores. En cualquier caso, con esta compra los miembros de la Comisión Protectora consumaban la misma operación que supuso la adquisición de literatura a través de la Biblioteca de La Nación, pero ahora cubrían saberes muy diferentes. Entre ellos, principalmente, una gama de conocimientos comprendidos dentro de ingeniería (mecánica e industrial), química, física, medicina doméstica e higiene, derecho, oficios varios y, en menor medida, libros sobre historia, ciencias sociales, política, economía y contabilidad. Aunque los Manuales Soler fue la compra principal en materia de ciencias naturales, exactas y aplicadas, no fue, sin embargo, la única. También fueron adquiridos los 30 volúmenes de la colección: Pequeña Enciclopedia de Química Industrial Práctica, de la editorial Bailly-Baillière, dirigida por F. Billón. Este repertorio, elaborado desde el punto de vista de la producción, comprendía nociones y técnicas sobre el procesamiento de la sal, el azúcar, el alcohol, las harinas y la leche; incluía, asimismo, temas relacionados con la industria maderera, minera y metalúrgica.

En ese contexto temático, el segmento dedicado a la producción agropecuaria requirió una atención especial. Mientras estaban en progreso las adquisiciones de las obras descriptas, Obligado puso a consideración de Rodríguez un proyecto para dividir el mapa de la Argentina en cuatro regiones productivas $\mathrm{y}$, en función de las cualidades ambientales de cada una, remitir un lote de libros que se ajustara a ellas (Comisión Protectora, 1908-192?, Acta 50, pp. 76-76, 22 de diciembre de 1914). Aprobada la propuesta, quedaron establecidas cuatro áreas: (1) Región subtropical, integrada por Jujuy, Salta, Chaco, Formosa, Corrientes (norte), Santa Fe (norte) y Misiones, a la que se destinarían obras sobre el cultivo de la caña de azúcar, naranjos, limones, mandarinas, arroz, algodón, yerba mate y tabaco, además de textos vinculados a la industria maderera, azucarera y ganadera. (2) Región andina y central, formada por Mendoza, San Juan, La Rioja, Catamarca, San Luis, Santiago del Estero, Córdoba y el Territorio de los Andes, para la que se escogerían estudios sobre vinicultura, minería, hidráulica y cría de mulas y cabras. (3) Región del litoral, compuesta por Santa fe (sur), Corrientes (sur), Entre Ríos y Buenos Aires, en la que primarían trabajos de agricultura cerealera (trigo, maíz, cebada, avena, centeno) y forrajera, tratados de ganadería y medicina veterinaria, y obras sobre curtiembre y fabricación de embarcaciones. Por último, (4) los Territorios nacionales del sur: La Pampa, Río Negro, Neuquén, Chubut, Santa Cruz, Tierra del Fuego. Para esta región el énfasis estaba puesto en la fruticultura (manzanas, peras, membrillos, guindas y cerezas) y la cría de lanares, junto con las industrias forestales, mineras, petroleras y pesqueras. No hubo, en los hechos, una especialización de la colección igual de exhaustiva a la que habilita imaginar este desglose (que en el documento es más detallado). Esto se debió, otra vez, a la imposibilidad en término de tiempo y dinero que suponía para la Comisión Protectora preparar repertorios con distintas características. Por las mismas razones antes vistas, Rodríguez propuso elaborar una base general y agregar, eventualmente, algunos títulos adecuados al medio productivo de cada biblioteca. La primera medida que se tomó en este sentido fue la adquisición de 4.000 ejemplares a \$2.000 de la colección: Biblioteca Rural Argentina. Su editor, Ramón A. Lastra, había dirigido en el inicio del novecientos la Revista de ganadería, veterinaria y agricultura (1901¿?), y entre 1911 y 1913 publicó el Almanaque del campo y álbum rural. Hasta donde fue posible constatar, la serie monográfica estaba compuesta por 14 títulos, que aparecieron entre 1906 y 1912, aunque no todas las impresiones y reimpresiones parecen haber salido bajo el sello que identifica a la colección. El propio Lastra fue el compilador de nueve volúmenes y un folleto: Arboricultura (2 tomos), Las aves de corral, El cultivo del trigo y del maiz, Lecturas rurales, El cultivo de la alfalfa, Leche, crema y manteca, Manual práctico de Medicina Veterinaria, Plantas forrajeras, Los árboles frutales, Abono de las vinas (folleto). Otros cuatro autores completan la nómina: Henriquez (Los abonos y las enmiendas de los suelos agricolas), Lecler (Las razas lanares y vacunas...), Posse (La cria e industria del cerdo) y Quevedo (Las epizootias del ganado argentino). A este repertorio básico, la Comisión Protectora le añadió 16 obras, en general, coincidentes con las áreas de producción diagramadas. Así, por ejemplo, fueron comprados libros sobre avicultura y tambo (vaca y 
cabra); cultivo de algodón, tabaco, olivo y arroz. Entre los autores nacionales, se destacan Ameghino (Las secas: y las inundaciones en la provincia de Buenos Aires), Castex (El tratamiento especifico de la tuberculosis) y Daireaux (La cria del ganado en la estancia moderna; Manual del agricultor argentino). Cierran la lista algunas publicaciones oficiales del Ministerio de Agricultura.

\section{Políticas Bibliotecarias y COLECciones DE LECTURAS}

La reconstrucción y el análisis del catálogo de las bibliotecas elementales, junto con las razones políticas y culturales que justificaron su elaboración, contribuyen a comprender las dimensiones específicas que adquirieron las estrategias estatales de nacionalización en el campo bibliotecario, más concretamente en manos de la Comisión Protectora de Bibliotecas Populares durante la segunda década del siglo XX. Los testimonios recogidos de la Memoria que la entidad publicó en 1917 en la que se declaran las intenciones bajo las cuales se formaron las colecciones elementales y los propósitos de su lanzamiento al espacio público confirman, de manera inequívoca, la adhesión a un supuesto según el cual la lectura, la práctica de la lectura, estaba investida de un poder de convencimiento significativo. Solo sobre esta base conceptual resultaba legítima la pretensión de expandir el sentimiento de argentinidad a partir de un corpus de libros escogidos y remitidos a diferentes puntos del país, donde serían usados por un lectorado amplio, de inquietudes variadas y atento a las novedades editoriales, pero cuya formación requería la mediación de una agencia (la biblioteca) que pudiera discriminar la buena lectura de la mala, distinguir la literatura recreativa y de calidad del entretenimiento escandaloso o sencillamente corrupto, separar, por fin, la historia de los héroes de la patria de las interpretaciones de la realidad formadas sobre la base de las teorías sociales foráneas. De ese modo, las colecciones que prefirió la entidad se alejaron del ámbito de las ideas difundidas por las izquierdas, a la vez que se distanciaron del segmento de literatura popular identificado con el criollismo y las novelas sentimentales.

Pero si el problema de la cohesión social y la demanda de nacionalización se canalizó en la misma época mediante series ordenadas de autores y temas ligados a la construcción de una tradición, como en el caso de la Biblioteca Argentina de Rojas, en su proyecto la Comisión Protectora no apostó como única estrategia por una lista jerarquizada de nombres y títulos que repusieran algo así como una épica de la Argentina, sino que más bien elaboró un modelo general de lectura anclado en valores mesocráticos de amplio espectro. La compra en grandes cantidades de los libros de la Biblioteca de La Nación, con su repertorio de literatura universal y novedosa, confirman esa orientación. Del mismo modo afirma esa tendencia la inclinación cientificista que se introdujo mediante la adquisición no menos cuantiosa de las misceláneas que caen bajo el rótulo amplio de las ciencias aplicadas, entre las que se aprecia un programa dedicado al sistema productivo del país (agricultura, ganadería, industrias básicas). En definitiva, desde la biblioteca no era posible contribuir a solucionar los problemas culturales y sociales con puros ensayos de interpretación o con la sola introducción de los clásicos del XIX. La biblioteca debía cubrir otras necesidades como las más obvias consultas de referencia, pero también los requerimientos del sistema de instrucción pública —estudiantes, maestras, funcionarios-, o las inquietudes de cualquier lector o lectora al paso. Por otro lado, no se debe olvidar que las bibliotecas elementales, tal y como fueron concebidas, apuntaban a reforzar un sistema bibliotecario que se consideraba insuficiente. Algunas de esas colecciones buscaron apuntalar la presencia del Estado en los barrios obreros de ciudades como Rosario, pero muchas otras encontraron destino en poblaciones que aún no disponían de una institución de este tipo, de manera que, en este contexto, una biblioteca elemental venía a llenar un vacío material y simbólico.

El modo en que la Comisión Protectora formó la biblioteca elemental sugiere, por otro lado, una operación que yuxtapuso diversas colecciones de editoriales - de literatura, de ciencias, de educación, de agricultura - para formar un solo repertorio. Existieron, desde luego, limitaciones en términos de tiempo, presupuesto e infraestructura que impidieron, según los propios funcionarios, analizar título a título las obras. Pero el 
beneficio de la incorporación de series ya escogidas de autores y temas no solo se midió en términos de atajos y economías. El movimiento supuso trasvasar el prestigio que cada editorial había ganado en el mercado hacia el catálogo de la biblioteca; significó apropiarse de la publicidad y la pátina de novedad por la que tanto invirtieron los editores de las primeras décadas del siglo XX en los diarios, los magazines y la vía pública; implicó, por último, señalizar el camino que debían seguir los futuros administradores de las bibliotecas elementales: bastaba con proseguir la adquisición de lo que estaba fijado como potencia. En este último sentido, las bibliotecas elementales fueron diseñadas como expresiones prospectivas. Todas las adquisiciones que la Comisión Protectora escogió de manera aislada apuntaron a reforzar aquello que ya había sido escogido a través de la mediación editorial, y a reunir los ensayos de interpretación nacional, que no habían sido objeto de ninguna serie hasta las intervenciones de Rojas e Ingenieros - cuyos primeros números salieron casi de forma simultánea a la formación de la primera generación de bibliotecas elementales-.

Finalmente, al considerar que el campo bibliotecario era un ámbito competitivo, al evaluar que las lecturas escogidas implicaron una exclusión forzada de otras posibilidades, al sumergir los nombres, los títulos, los temas y las figuras en un modelo de lectura más amplio, las bibliotecas elementales valieron más por el dispositivo mismo que por el canon que instituyeron, es decir, su cualidad como política fue la extensión de una comunidad imaginada de lecturas que se apoyó en un repertorio que, en sí mismo, representaba el conocimiento autorizado y el marco modélico de las futuras elecciones.

\section{FUENTES DOCUMENTALES}

Beltrán y Rózpide, R. (1904). La Guinea Española. Barcelona: Gallach. (Manuales Soler; 17; Manuales Gallach; 17). Recuperado de: http://bdh-rd.bne.es/viewer.vm?id=0000108303\&page $=1$

Biblioteca de La Nación. Volúmenes existentes. La Nación, 3 de enero de 1914.

Catálogo de los libros existentes de la Biblioteca de La Nación liquidados por la agencia Aymará. Buenos Aires, 1920.

Comisión Protectora de Bibliotecas Populares. Libro de actas $n^{\circ} 1$ de la Comisión Protectora de Bibliotecas Populares, Buenos Aires, 1908-192?, Manuscrito. Recuperado de: http://www.conabip.gob.ar/archivo_his torico

Comisión Protectora de Bibliotecas Populares. "Biblioteca Popular General José de San Martín. San Roque, Corriente”. Expediente 19-S-15, 1914-1915. Recuperado de: http://v.conabip.gob.ar/archivo_hist orico/results/field_bp_historica\%253A29292

Comisión Protectora de Bibliotecas Populares (1917). Memoria de la Comisión Protectora de Bibliotecas Populares correspondiente a los años 1915 y 1916. Buenos Aires: Talleres Gráficos de L. J. Rosso.

Giménez, Á. (1918). Nuestras Bibliotecas Socialistas: notas y observaciones. Buenos Aires: L. J. Rosso.

Giménez, Á. (1932). Nuestras Bibliotecas Obreras: notas, observaciones, sugestiones. Buenos Aires: La Vanguardia.

Ministerio de Justicia e Instrucción Pública (1908). Decreto sobre bibliotecas populares de 3 de julio de 1908 y mensaje explicativo. Buenos Aires: Talleres Gráficos de la Penitenciaria Nacional.

Zeballos, E. (1904). Lo que dicen de los Manuales-Gallach. El Sabio Dr. E. S. Zeballos de Buenos Aires. En Beltrán y Rózpide, R. La Guinea Española. Barcelona: Gallach. (Manuales Soler; 17; Manuales Gallach; 17). Recuperado de: http://bdh-rd.bne.es/viewer.vm?id=0000108303\&page $=1$

\section{REFERENCIAS}

Adamovsky, E. (2019). El gaucho indómito. De Martín Fierro a Perón, el emblema imposible de una nación desgarrada. Buenos Aires: Siglo XXI.

Altamirano, C. y Sarlo, B. (2016). Ensayos argentinos, de Sarmiento a la vanguardia. Buenos Aires: Siglo XXI. 
Bertoni, L. A. (2001). Patriotas, cosmopolitas y nacionalistas. La construcción de la nacionalidad argentina a finales del siglo XIX. Buenos Aires: Fondo de Cultura Económica.

Degiovanni, F. (2007). Los textos de la patria: nacionalismos, políticas culturales y canon en Argentina. Buenos Aires: Beatriz Viterbo.

De Sagastizábal, L. (1995). La edición de libros en la Argentina. Una empresa cultural. Buenos Aires: EUDEBA.

Di Stefano, M. (2013). El lector libertario: prácticas e ideologías lectoras del anarquismo argentino (1898-1915). Buenos Aires: Eudeba.

Fiebelkorn, A (2018). Miradas de inspección: las bibliotecas populares del partido de La Plata según los informes de la Comisión Protectora, 1919-1945. Historia y Espacio, 14(51). http://doi.10.25100/hyev14i51.6986

Guereña, J. L. (2017). Las primeras colecciones populares de divulgación sexual en España (finales del siglo XIXcomienzos del siglo XX). En C. Rivalan Guégo y M. Nicoli (Comps.), La colección. Auge y consolidación de un objeto editorial (Europa/América, siglos XVIII-XXI) (pp. 157-173). Bogotá: Universidad de los Ándes, Ediciones Uniandes, Universidad Nacional de Colombia.

Halperín Donghi, T. (2017). ¿Para qué la inmigración? Ideología y política inmigratoria en la Argentina (1810-1914) (pp. 187-235). El Espejo de la Historia. Buenos Aires: Siglo XIX.

Merbilhaá, M. (2006). La época de organización del espacio editorial. En: J. L. de Diego (Dir.), Editores y politicas editoriales en Argentina, 1880-2000 (pp. 29-58). Buenos Aires: Fondo de Cultura Económica.

Palierne, F. (2017). La declaración de intención, una identidad entre manifiesto y peritexto comercial: aproximaciones al discurso de intención en las colecciones literarias de la segunda mitad de siglo XX. En C. Rivalan Guégo y M. Nicoli (Comps.), La colección. Auge y consolidación de un objeto editorial (Europa/América, siglos XVIII-XXI) (pp. 29-48). Bogotá: Universidad de los Ándes, Ediciones Uniandes, Universidad Nacional de Colombia.

Parada, A E. (2005). El orden y la memoria en la librería de Duportail Hermanos. Un catálogo porteño de 1829. Buenos Aires: Instituto de Investigaciones Bibliotecológicas. Facultad de Filosofía y Letras. Universidad de Buenos Aires.

Parada, A. E. (2008). Los libros en la época del salón literario. El catálogo de la Librería Argentina de Marcos Sastre (1835). Buenos Aires: Académica Argentina de Letras.

Planas, J. (2017). Libros, lectores y sociabilidades de lectura. Una historia de los origenes de las bibliotecas populares en la Argentina. Buenos Aires: Ampersand.

Planas, J. (2019). Los discursos bibliotecarios sobre la lectura en la Argentina durante las primeras décadas del siglo XX. Algunas claves para la constitución de un objeto de conocimiento. Políticas de la Memoria, 19, 233-243. Recuperado de: https://ojs.politicasdelamemoria.cedinci.org/index.php/PM/article/view/570/649

Planas, J. (2021). Bibliotecas populares elementales. Nacionalismo, inmigración y política bibliotecaria durante la década de 1910. Prismas. Revista de historia intelectual, 25. En prensa.

Rivera, J. B. (1980). La forja del escrito profesional. Capitulo. Historia de la literatura argentina. Buenos Aires: 1980, 56.

Rodríguez Giavarini, F. (2018). Modernidad in octavo para una Argentina lectora. Aspectos materiales y visuales de la Colección Biblioteca La Nación (1901-1920). Tesis de Maestría en Historia del Arte Argentino y Latinoamericano IDAES Universidad Nacional de San Martin. Recuperado de http://ri.unsam.edu.ar/bitstrea $\mathrm{m} /$ handle/123456789/821/TMAG\%20IDAES\%202018\%20RGMF.pdf?sequence=1\&isAllowed=y

Sánchez Vigil, J. M. y Olivera Zaldua, M. (2013). La editorial Gallach y su contribución a la industria cultural española: Recuperación y análisis de su catálogo. Investigación bibliotecológica, 28(63), 51-83. Recuperado de: http://www .scielo.org.mx/scielo.php?script=sci_arttext\&pid=S0187-358X2014000200004\&lng=es\&tlng=es

Sarlo, B. (1985). El imperio de los sentimientos. Buenos Aires: Catálogos.

Severino, J. E. (1996). Biblioteca de La Nación (1901-1920). Los anaqueles del pueblo. Boletín de la Sociedad de Estudios Bibliográficos, 1 .

Seoane Cerraga, J. B. (2015). Pedagogía del cuerpo y educación sexual en la España contemporánea. Una aproximación genealógica a través de las polémicas suscitadas en torno a los manuales destinados a la infancia y la adolescencia. 
Itinerario Educativo, 66, 347-377. Recuperado de: https://revistas.usb.edu.co/index.php/Itinerario/article/vie $\mathrm{w} / 2226 / 1948$

Sik, M. E. (2018). La creación de bibliotecas durante el apogeo del anarquismo argentino, 1898-1905. Historia y Espacio, 14(51). http://doi.10.25100/hye.v14i51.6984

Suriano, J. (2008). Anarquistas: cultura y politica libertaria en Buenos Aires (1890-1910). Buenos Aires: Manantial.

Terán, O. (2000). Vida intelectual en el Buenos Aires de fin de siglo (1880-1910). Derivas de la cultura cientifica. Buenos Aires: Fondo de Cultura Económica.

Tarcus, H. (2013). Marx en la Argentina: susprimeros lectores obreros, intelectuales y cientificos. Buenos Aires: siglo XXI.

Tripaldi, N. (1997). Origen e inserción de las bibliotecas obreras en el entorno bibliotecario argentino: fines del siglo XIX y primer tercio del siglo XX. Libraria: Correo de las Bibliotecas, 1(1).

Wilson, P. (2004). La constelación Sur. Traductores y traducciones en la literatura argentina del siglo XX. Buenos Aires: Siglo XXI.

\section{Notas}

1 A finales de 1913 un cortocircuito producido por el recorte presupuestario para la Comisión Protectora acabó con la renuncia de sus miembros, que se reincorporaron un año más tarde. Durante ese interregno, la entidad funcionó, hasta donde fue constatado, con el personal estable de oficina. Este episodio explica la ausencia de estadística para el año 1914. 